\title{
Correlation and Path Coefficient Analysis in Seed Yield and Yield Related Traits Black Cumin (Nigella sativa L.) Genotypes, at Debre-Zeit, Central Ethiopia
}

\author{
Yewubdinber lemma \\ Crop and Horticulture Directorate, Ethiopian Biodiversity Institute,P.O.Box:30726, Addis Ababa, Ethiopia
}

\begin{abstract}
Black cumin (Nigella sativa L.) is spice which are used as herbal medicine. To study correlation and path coefficient analysis for seed yield and oil content by using $5 \times 5$ simple lattice design for 25 black cumin genotypes at Debre-Zeit Agricultural Research Center during 2018/19 cropping season. For this evolution to used 12 characters seed yield and yield related traits. Number of primary branches per plant, secondary branches per plant, number of capsules per plant thousand seed weight, plant height, and number of seeds per capsule are positive and significant correlation with seed yield at both genotypic and phenotypic levels. Seed yield had also significant phenotypic correlation with oleoresin content of seeds. In path coefficient analysis number of primary and secondary branches per plant, number of capsules per plant and number of seeds per capsule plant height, had showed positive direct effects on seed yields at genotypic level. Then again thousand seed weight, plant height, number of seeds per capsule, number of capsule and number of seed per capsulehad positive direct effect on seed yield at phenotypic level.This study showed that Correlation studies provide a better understanding of yield components with seed yield helps the plant breeder during selection in black cumin genotypes.
\end{abstract}

Keywords:Black cumin, Correlation, path coefficient, Genotypes, phenotypes

DOI: $10.7176 / \mathrm{JBAH} / 12-2-02$

Publication date: January $31^{\text {st }} 2022$

\section{Introduction}

Black cumin (Nigella sativa L.) is plants which are used as aspice and medicinal plants, which belongs to a family of Rananculacea. It is originated in Egypt and East Mediterranean. The seed is growthed in many countries in the world like Middle Eastern, South Europe, Turkey and Syria (Datta et al., 2012 ).

The composition like, minerals, vitamins alkaloids, histidine, isoleucine,leucine,lysine are found in black cumin seed (Tembhurne et al., 2014; Rezaei Chiyaneh et al., 2018]..The investigations of the seed extracts reveal abroad spectrum of activities including galactagogic and insect repellant effects (Ramadan 2018; Saleh, 2018). The seed of black cumin from Ethiopia containing different compound like a monocyclic, phenolic thymol, The seed of black cumin is functioned us in industry in ingredient in preparing soup, cheese cakes and candies and used as medicinal purposes(Forouzanfar et la., 2014; Amin and Hosseinzadeh 2016).

A correlation analysis is giving information about the degree of the relation between the important characters and predicts the good character that used for change of particular trait. It helps in determine the direction and the characters to be consider in improving the yield .Correlated characters are of main importance because of genetic causes of correlations through pleiotropic action or progressive interactions of genes and changes carried about by a natural or artificial selection (Falconer et al., 1996; Sharma, 1998).). In path coefficient analysis the yield effected by the character directed or in directed effects and thus components provide information for future breeding program. Therefore the study of correlation and Path Coefficient Analysis of the trait important to determine the trait that have greater association with seed yield and for various yield and yield contributing traits in black cumin genotypes.

\section{Materials and Methods}

\subsection{The experimental Site}

The research was conducted at Debre-Zeit Agriculture Research Center (DZARC) in the 2018 Debre-Zeit is found at $08^{\circ} 44^{\prime} \mathrm{N}$ latitude and $38^{\circ} 58^{\prime} \mathrm{E}$ longitude and it far from Addis Ababa the capital city of Ethiopia on the south east direction by $47 \mathrm{~km}$ at an altitude of $1860 \mathrm{~m}$.a.s.l. The site received an annual rainfall of $1151.6 \mathrm{~mm}$ and the area has minimum temperature of 19.03 and maximum temperature of $26.91^{\circ} \mathrm{C}$. The essential oil and oleoresin contents of the seeds were determined at Wondo Genet agricultural research center, using methods described in the section on data collection.

\subsection{Experimental Materials and Design}

25 genotypes were evaluated during conducting the research. The genotypes were collected from Oromiya Regional State by Ethiopian Biodiversity Institute. Genotypes were evaluated in 5 x 5 simple lattice designs. The seeds were drilled in rows spaced $30 \mathrm{~cm}$ each other and a distance of $15 \mathrm{~cm}$ between plants in to each row. The 
plot of one genotypes had $3 \mathrm{~m}$ long and $1.80 \mathrm{~m}$ wide $\left(3 \times 1.8 \mathrm{~m}=5.4 \mathrm{~m}^{2}\right)$. The spacing between two plots within the same block was $50 \mathrm{~cm}$ and the spacing between blocks was $1 \mathrm{~m}$ and the spacing between the replications was 2 .The design and randomization were done as per the standard procedure set by Cochran and Cox (1957).

\subsection{Data Collection}

The data of the information were collected from whole plots and ten randomly selected samples of plants; and the data were recorded for the following parameters. Days to $50 \%$ emergence, days to flowering, days to $50 \%$ flowering, flowering duration, days to $90 \%$ maturity, plant height, thousand seed weight,seed yield number per capsule, number of seeds per capsule, number of primary and secondary branches, oleoresin and essential oil content. Oleoresins and essential oils extraction and determination was made following the standard methods of AOAC (2005). The percentage oil yield was calculated as suggested by (Rao et al. (2005) as follows formula (1) Percentage yield of oil $(\%)=\frac{\text { mass of oil }}{\text { mass of the seed sample }} * \mathbf{1 0 0}$

\subsection{Data Analysis}

\subsubsection{Phenotypic Correlation Coefficient Analysis}

Phenotypic (rp) correlations between two traits were estimated using the formula (2) suggested by Johnson et al. (1955)

$$
r p x y=\frac{\operatorname{covpxy}}{\sqrt{\sigma^{2} \mathrm{px} \cdot \sigma^{2} p y}} \ldots \ldots \ldots \ldots \ldots(2)
$$

Where, $r p x y=$ phenotypic correlation coefficient between character $\mathrm{x}$ and $\mathrm{y}$ covpxy $=$ phenotypic covariance between character $\mathrm{x}$ and $\mathrm{y}$ $\sigma^{2} \mathrm{px}=$ phenotypic variance for character $\mathrm{x}$ $\sigma^{2} p y=$ phenotypic variance for character $y$

\subsubsection{Genotypic Correlation Coefficient Analysis}

genotypic (rg) correlations between two traits were estimated using the formula (3) suggested by Johnson et al. (1955)

$$
r g x y=\frac{\operatorname{covg} x y}{\sqrt{\sigma^{2} g x \cdot \sigma^{2} g y}}
$$

Where, $r g x y=$ genotypic correlation coefficient between character $\mathrm{x}$ and $\mathrm{y}$ $\operatorname{covg} x y=$ genotypic covariance between character $\mathrm{x}$ and $\mathrm{y}$ $\sigma^{2} g x=$ genotypic variance for character $\mathrm{x}$ $\sigma^{2} g y=$ genotypic variance for character $y$ The coefficient of correlation at phenotypic level was tested for significance by comparing the values of correlation coefficient with tabulated $\mathrm{r}$ value at $\mathrm{g}-2$ degree of freedom, where ' $\mathrm{g}$ ' is number of genotypes. However, the coefficient of correlations at genotypic level was tested for the significance using the formula (4) described by Robertson (1959).

$$
\mathrm{t}=\frac{(\operatorname{rgxy})}{\operatorname{SErgxy}}
$$

The calculated ' $t$ ' value was compared with the tabulated', value at g-2 degree of freedom at $5 \%$ level of significance. Where, g= number of genotypes, $r g x y=$ genotypic correlation coefficient and $\operatorname{SEr} g x y=$ standard error of genotypic correlation coefficient between character $\mathrm{x}$ and $\mathrm{y}$ which will be calculated as formula (5):

$\boldsymbol{S} \boldsymbol{E}_{\text {rgxy }}=\sqrt{\frac{\left(1-\mathrm{r}^{2}\right)^{2}}{2 H^{2} x \cdot H^{2} y}}$.

Where: $\boldsymbol{S E}_{\boldsymbol{r g x y}}=$ standard error of genotypic correlation coefficient between character x and y, $H^{2} x=$ Heritability value of character $\mathrm{x}$ and $H^{2}{ }_{y}=$ heritability value of character $\mathrm{y}$.

\subsubsection{Path Analysis}

In genotypic and phenotypic correlations, path coefficient analysis which refers to the assessment of direct and indirect effects of the seed yield attributing characters (independent character) on seed yield (dependent character) would calculated the method used by Dewey and $\mathrm{Lu}(1959)$ as follows formula(6):

$r i j=p i j+$ Srikpkj.

Where, $r i j=$ mutual association between the independent character (i) and dependent character (j) as measured by the genotypic and phenotypic correlation coefficients. $p i j=$ direct effects of the independent character (i) on the dependent variable (j) as measured by the genotypic path coefficients, and $\Sigma r i k p k j=$ Summation of components of indirect effects of a given independent character (i) on a given dependent character (j) via all other independent characters $(\mathrm{k})$.

The residual effect, which shows how best the causal factors account for the variability of the dependent factor yield, will be computed using the formula(7); 
$1=p^{2} R+$ Spijrij

Where, $p^{2} R$ is the residual effect and $\Sigma p i j r i j$ is the product of the direct effect of any variable and its correlation coefficient with yield.

\section{Results and Discussion}

\subsection{Genotypic and Phenotypic Correlation Coefficients of Seed Yield with Other Characters}

The results of genotypic and phenotypic coefficients of correlations are presented in Table 1. plant height, number of capsules per plant, number of primary branches per plant and number of seeds per capsule had positive and significant correlation coefficients with Seed yield at both genotypic and phenotypic levels and number of the secondary branch and thousand seed weight had positive and significant correlation coefficient with seed yield at the phenotype level. The observed positive and significant correlations of seed yield with that above trait except another trait that is a negative and nonsignificant correlation with seed yield suggested that the selection of genotypes for one trait does not affect the seed yield. Association between traits could be due to genotypic correlation, which is attributed to linkage between genes or pleiotropic gene effect, or due to environmental correlation, or both (Falconer and Mackey,1996).

The analysis of indices allows the direct effects of each trait on seed yield and also helps to be separate from indirect effects existing in mutual relations of different traits (Mokhtassi, et al.,2006) . In this study results:- plant height, number of capsules per plant, number of primary branches per plant, thousand seedweight and number of seeds per capsule had positive and significant correlations with seed yield. This could be an suggestion for the selection program of black cumin to focus primarily on plant height, number of primary branch and number of capsules per plant, if the intention is to go for high yield. Similar results were reported by Tewodros et al. (2018).

\subsection{Genotypic and Phenotypic Correlation Coefficients among Other Characters}

Day to first flowering showed a positive and significant phenotypic correlation with day to $50 \%$ flowering, day to maturity, plant height, the number of capsule and number of primary branches (Miheretu,2018). Day to first flowering showed a positive and significant genotypic correlation with day to $50 \%$ flowering, day to maturity, plant height number of primary branch, number of seed per capsule and the number of capsules and. it had negative and significant genotypic correlation with thousand seed weight (Tewodros et al. 2018). .

Number of capsule per plant had a positive and significant phenotypic correlation with days to first flowering, day to maturity, seed yield, number of seed per capsule, number of primary and secondary branch and plant height. It showed positive genotypic correlation with seed yield, number of seed per capsule, number of primary and secondary branch and plant height (Preeti et al., 2019) .

Plant height had a positive and significant phenotypic correlation with day to maturity the number of capsule, the number of primary and secondary branch and seed yield. It had a positive and significant genotypic correlation with number of primary branch, seed yield, number of capsule and thousand seed weight (Tewodros,2018 and Preeti et al.,2019). Generally, positive correlation of any pairs of traits of the present black cumin genotypes indicated the possibility of correlated response to selection. In contrary to this, the negative correlation prevents the simultaneous improvement of those traits along with each other.

Table 1. Estimates of genotypic (above diagonal) and phenotypic (below diagonal) coefficients of correlations among 12 traits in black cumin genotype

\begin{tabular}{lllllllllllll}
\hline Variable & Dff & Dpf & DnpM & TSW & SY & PH & NPB & NSB & NC & NSpC & OLR & ESS \\
\hline Dff & 1 & $0.90^{* *}$ & $0.84^{* *}$ & $-0.28^{*}$ & 0.29 & $0.31^{*}$ & $0.33^{* *}$ & 0.04 & $0.34^{* *}$ & $0.35^{*}$ & 0.19 & 0.12 \\
Dpf & $0.81^{* *}$ & 1 & $0.94^{* *}$ & $0.34^{*}$ & 0.33 & 0.04 & 0.30 & -0.10 & 0.13 & -0.15 & 0.03 & 0.21 \\
DnpM & $0.78^{* *}$ & $0.94^{* *}$ & 1 & 0.19 & 0.29 & $0.39^{*}$ & 0.26 & -0.11 & $0.37^{*}$ & -0.24 & 0.27 & 0.18 \\
TSW & 0.10 & 0.06 & -0.03 & 1 & $0.26^{*}$ & $0.37^{*}$ & 0.17 & -0.07 & 0.11 & 0.05 & $0.43^{*}$ & 0.09 \\
SY & $-0.28^{*}$ & 0.24 & 0.16 & $0.58^{* *}$ & 1 & $0.82^{* *}$ & $0.58^{* *}$ & $0.48^{*}$ & $0.70^{* *}$ & $0.54^{*}$ & 0.27 & 0.19 \\
PH & $0.24^{*}$ & 0.19 & $0.22^{*}$ & -0.20 & $0.65^{* *}$ & 1 & $0.23^{*}$ & $0.25^{*}$ & $0.27^{*}$ & -0.15 & -0.05 & -0.01 \\
NPB & $0.23^{*}$ & $0.33^{*}$ & $-0.27^{*}$ & 0.15 & $0.38^{* *}$ & $0.19^{*}$ & 1 & $0.37^{*}-$ & $\mathbf{0 . 5 1}^{* *}$ & $\mathbf{0 . 2 1}^{*}$ & -0.07 & -0.13 \\
NSB & -0.05 & 0.02 & $-0.20^{*}$ & $-0.29^{*}$ & $0.36^{* *}$ & 0.14 & $0.32^{* *}$ & 1 & $0.45^{* *}$ & $0.22^{*}$ & -0.19 & -0.06 \\
NC & $0.33^{*}$ & 0.11 & $0.25^{*}$ & 0.12 & $0.43^{* *}$ & $0.35^{*}$ & $0.37^{* *}$ & $0.40^{* *}$ & 1 & $0.42^{*}$ & -0.06 & 0.08 \\
NSpC & 0.04 & 0.02 & $0.33^{*}$ & 0.13 & $0.49^{* *}$ & -0.04 & $0.22^{*}$ & $0.28^{*}$ & $0.38^{* *}$ & 1 & 0.34 & 0.07 \\
OLR & 0.18 & 0.07 & 0.08 & 0.24 & $0.36^{*}$ & -0.23 & -0.08 & 0.07 & 0.05 & $0.30^{*}$ & 1 & 0.03 \\
ESS & 0.23 & 0.04 & 0.02 & 0.17 & 0.39 & 0.04 & -0.06 & -0.09 & 0.05 & -0.11 & 0.19 & 1
\end{tabular}

Dff $=$ Days to first Flowering, DnpM= Days to $50 \%$ flowering, DnpM=Days to $90 \%$ maturity, TSW= Thousand seed weight, $\mathrm{SY}=$ SeedYield, $\mathrm{PH}=$ Plant Height, $\mathrm{NPB}=$ Number of Primary Branch, $\mathrm{NSB}=$ Number Secondary Branch, $\mathrm{NC}=$ Number of Capsule, $\mathrm{NSpC}=$ Number of Seed per Capsule, OLR=oleoresin, ESS $=$ essential oil, * symbol show Significant at $\mathrm{P}=0.05$ and, ${ }^{* *}$ symbol show Significant at $\mathrm{P}=0.01$ levels, 


\subsection{PathCoefficient Analysis}

\subsubsection{Phenotypic Path Coefficient Analysis of Seed Yield with Other Traits}

Path coefficient analysis at the phenotypic level, seed yield (SY) was considered as a variable that is dependent on independent variables, which were considered as causes. The independent characters were thousand seed weight $(0.35)$, plant height $(0.45)$, number of primary branches $(0.21)$, the number of secondary branches $(0.10)$, number of capsule per plant (0.29), number of seeds per capsule $(0.30)$ had direct positive effect on seed yield. (Table 2.) In phenotypic path coefficient analysis, number of seeds per capsule, number of capsule per plant, number of primary branches and the number of secondary branches had exerted positive direct effect on seed yield at phenotypic level (Gashaw, 2020). And also the number of capsule, number of seed per capsule was the most direct effect of traits on seed yield (Bardideh et.al., 2013). This show thus character that is direct effect important to improve seed yield for future breeding program.

Table 2.. Estimates of direct (bold diagonal) and indirect effect (off-diagonal) at phenotypic level for ten characters on grain yield in black cumin genotypes

\begin{tabular}{lrrrrrrrrrrrr}
\hline Variable & Dff & \multicolumn{1}{c}{ Dpf } & DnpM & TGW & \multicolumn{1}{c}{ PH } & NPB & NSB & NC & NSpC & OLE & ESS & Rp \\
\hline Dff & $\mathbf{0 . 0 1}$ & -0.19 & 0.04 & 0.02 & -0.20 & 0.01 & -0.01 & 0.02 & -0.01 & 0.02 & 0.01 & -0.28 \\
Dpf & 0.03 & $\mathbf{- 0 . 0 3}$ & 0.04 & 0.04 & 0.10 & 0.04 & 0.09 & 0.01 & 0.00 & 0.00 & 0.00 & 0.24 \\
DnpM & 0.04 & -0.04 & $\mathbf{- 0 . 0 5}$ & -0.01 & 0.02 & 0.15 & 0.09 & 0.04 & 0.03 & 0.01 & 0.01 & 0.16 \\
TGW & 0.02 & -0.01 & -0.01 & $\mathbf{0 . 3 5}$ & -0.01 & 0.02 & 0.20 & 0.02 & -0.01 & 0.01 & 0.01 & 0.58 \\
PH & -0.01 & -0.05 & 0.01 & 0.08 & $\mathbf{0 . 4 5}$ & 0.09 & 0.01 & -0.01 & 0.08 & -0.09 & 0.09 & 0.65 \\
NPB & 0.05 & -0.08 & 0.09 & 0.03 & 0.01 & $\mathbf{0 . 2 1}$ & -0.02 & 0.09 & -0.01 & 0.03 & -0.01 & 0.38 \\
NSB & 0.02 & 0.09 & 0.10 & -0.06 & -0.06 & 0.05 & $\mathbf{0 . 1 0}$ & 0.01 & 0.03 & 0.05 & 0.03 & 0.36 \\
NC & 0.10 & -0.03 & 0.12 & 0.02 & -0.05 & 0.01 & -0.02 & $\mathbf{0 . 2 9}$ & -0.04 & 0.01 & 0.02 & 0.43 \\
NSpC & 0.06 & -0.02 & 0.05 & 0.19 & -0.09 & 0.01 & -0.01 & 0.09 & $\mathbf{0 . 3 0}$ & 0.01 & -0.10 & 0.49 \\
OLE & 0.05 & 0.04 & 0.10 & 0.06 & 0.01 & 0.03 & 0.01 & 0.02 & 0.01 & $\mathbf{0 . 0 2}$ & 0.01 & 0.36 \\
ESS & 0.02 & -0.01 & 0.00 & 0.17 & 0.00 & 0.00 & 0.00 & 0.00 & 0.16 & 0.01 & $\mathbf{0 . 0 4}$ & 0.39 \\
\hline
\end{tabular}

Thousand seed weight, $\mathrm{PH}=$ Plant Height, $\mathrm{NPB}=$ Number of Primary Branch, $\mathrm{NSB}=$ Number Secondary Branch, $\mathrm{NC}=$ Number of Capsule, $\mathrm{NSpC}=$ Number of Seed per Capsule; residual effect $=0.031$

\subsubsection{Genotypic Path Coefficient Analysis of Seed Yield with Other Traits}

Path coefficient analysis at the genotypic level, seed yield (SY) was measured as a variable that is dependent on independent variables, which were considered as causes. The independent traits were plant height $(0.41)$, number of capsule per plant (0.36), number of primary branches $(0.29)$, number of seeds per capsule $(0.20)$ had direct positive effect on seed yield (Table 3). Plant height followed by number of capsules, number of primary branch and number of seed per capsule exerted positive direct effect on seed yield. Bardideh et al. (2013) reported number of capsule per plant, number of seed per capsule was direct effect on grain yield.

In genotypic path coffiecint analysis, number of capsules per plant, and number of primary branches showed positive direct effect on seed yield. promising direct effects of these traits on black cumin seed yield indicate that other variables reserved constant and improvement of these traits will increase seed yield. therefore, these traits should be kept in attention in the future breeding program of black cumin Gashaw,2020). In general, , path coefficient analysis is important to analyze and determine the traits having greater and true interrelationship with seed yield through separating of the correlation coefficient into direct and indirect effects. As a result of this, traits that exerted positive direct effect and positive and significant correlation with seed yield needs much attention in selection program.. Therefore, it is suggested that preference should be given to these characters in the selection programmed to separate good trait for higher yield in black cumin genotypes

Table 3..Evaluations of direct and indirect effect at a genotypic level for some characters on seed yield in black cumin genotypes.

\begin{tabular}{lllllllllllll}
\hline Variable & Dff & Dpf & DnpM & TSW & PH & NPB & NSB & NC & NSpC & OLE & ESS & Rg \\
\hline Dff & $\mathbf{- 0 . 0 1}$ & 0.08 & -0.01 & -0.03 & 0.01 & 0.04 & 0.01 & 0.09 & 0.05 & 0.02 & 0.05 & 0.29 \\
Dpf & 0.03 & $\mathbf{0 . 0 9}$ & 0.03 & 0.04 & 0.01 & -0.05 & 0.03 & 0.02 & 0.03 & 0.09 & 0.01 & 0.33 \\
DnpM & 0.06 & 0.01 & $\mathbf{0 . 0 8}$ & 0.03 & -0.08 & -0.05 & 0.02 & 0.06 & 0.08 & 0.03 & 0.05 & 0.29 \\
TSW & -0.05 & 0.04 & 0.07 & $\mathbf{- 0 . 0 1}$ & 0.09 & 0.01 & -0.07 & 0.02 & 0.05 & 0.05 & 0.06 & 0.26 \\
PH & -0.09 & 0.03 & 0.02 & 0.08 & $\mathbf{0 . 4 1}$ & 0.10 & -0.03 & 0.10 & 0.03 & 0.09 & 0.08 & 0.82 \\
NPB & 0.01 & 0.05 & 0.08 & 0.09 & -0.02 & $\mathbf{0 . 2 9}$ & 0.04 & 0.08 & -0.05 & 0.03 & -0.01 & 0.58 \\
NSB & 0.03 & 0.09 & 0.05 & -0.04 & -0.14 & -0.08 & $\mathbf{0 . 1 5}$ & 0.31 & -0.04 & 0.08 & 0.07 & 0.48 \\
NC & -0.08 & 0.07 & -0.08 & 0.01 & 0.23 & -0.09 & 0.10 & $\mathbf{0 . 3 6}$ & 0.08 & 0.01 & 0.09 & 0.70 \\
NSpC & -0.02 & 0.04 & 0.05 & 0.03 & 0.28 & -0.15 & 0.04 & 0.05 & $\mathbf{0 . 2 0}$ & 0.01 & 0.01 & 0.54 \\
OLE & 0.08 & 0.04 & 0.01 & 0.05 & 0.01 & 0.03 & 0.01 & 0.01 & 0.01 & $\mathbf{0 . 0 1}$ & 0.01 & 0.27 \\
ESS & 0.01 & 0.02 & 0.06 & 0.05 & -0.01 & 0.08 & -0.01 & 0.01 & 0.03 & 0.05 & $\mathbf{0 . 1 0}$ & 0.39 \\
\hline
\end{tabular}

$\mathrm{TSW}=$ Thousand Seed WeightPH=Plant Height, NPB=Number of Primary Branch, NSB= Number Secondary Branch, $\mathrm{NC}=$ Number of Capsule, $\mathrm{NSpC}=$ Numbser of Seed per Capsule, residual effect $=0.022$ 


\section{Conclusion}

In conclusion, Plant height, number of capsules per plant, number of primary branches per plant and number of seeds per capsule had positive and significant correlation coefficients with seed yield both at both genotypic and phenotypic levels and at the phenotype level number of secondary branch and thousand seed weight had positive and significant correlation coefficient with seed yield. So, from correlation studies to get information that are important for direction of selection. The results obtained from path analysis of showed that plant height, thousand seed weight, number of seeds per capsule, number of capsule and number of seed per capsule had positive direct effect on seed yield at phenotypic level. On the other hand plant height, number of primary branches, number of capsule per plant, number of seeds per capsule had direct positive effect on seed yield at genotypic level.

\section{Conflicts of Interest}

The authors declare that there are no conflicts of interest.

\section{Acknowledgments}

The authors are to acknowledge Haramaya University and Ethiopian biodiversity institution, for providing genetic material and Haramaya University for providing research funds.

\section{References}

Datta A. K., Saha A., Bhattacharya A.(2012). Black cumin (Nigella sativa L.), A review.Journal of Plant Development Sciences,vol.4, no.1, pp.1-43.

Tembhurne S.V.,Feroz S., More B.H., Sakarkar D.M.(2014). A review of the therapeutic potential of Nigella sativa (kalonji) seed, Journal of Medicinal Plants Rese arch, vol.8,no.3,pp.167-177.

Rezaei-Chiyaneh E., Seyyedi S.M., Ebrahimian E., Moghaddam SS., Damalas CA. (2018). Exogenous application of gamma-aminobutyric acid (GABA) alleviates the effect of water deficit stress in black cumin (Nigella sativa L.), Ind Crops Prod, no.112, pp.741-748.

Ramadan M.F. (2018). Nutritional value and applications of Nigella sativa essential oil: a mini review, Journal of Essential Oil Research,vol. 27,no.4,pp. 271-275.

Saleh F.A., El-Darra N., Raafat K., El-Ghazzawi I. (2018). Phytochemical analysis of Nigella sativa L. utilizing GC-MS exploring its antimicrobial effects against multidrug-resistant bacteria, Pharmacogn Journal, vol.10,no.1,pp.99-105.

Forouzanfar F., Bazzaz B.S.F., Hosseinzadeh H. (2014). Black cumin (Nigella sativa) and it's constituent (thymoquinone): a review on antimicrobial effects, Iranian journal of basic medical sciences, vol. 17, no.12,p.929.

Amin B., Hosseinzadeh H. (2016). Black cumin (Nigella sativa) and its active constituent, thymoquinone: an overview on the analgesic and anti-inflammatory effects, Planta medica, vol.82,no.01/02), pp.8-16.

Falconer D.S, Mackay T.F.C. (1996). An introduction to quanitative genetic Ed, 4.Hall London,

Sharma J.R. (1998). Statistical and Biometrical Techniques in Plant Breeding, New Age International (P) Limited Publishers, New Delhi. Pp 432.

Cochran W., Cox G. (1957). Completely randomized, randomized block and Latin square designs experimental design.

Rao B.R., Kaul P.N., Syamasundar K.V., Ramesh S. (2005). Chemical profiles of primary and secondary essential oils of palmarosa (Cymbopogonmartinii (Roxb.)Wats var. motia Burk.) nIndustrial Crops and Products, vol.21,no.1,pp.121-127.

AOAC.(2005). Official Methods of Analysis.Association of Official Analytical Chemists, $18^{\text {th }}$ Edition, Washington, DC.

Johnson H.W., Robinson H. F., Comstock R. E. (1955). Estimation of the genetic and environmental variability of soybean, Agronomy Journal, no.47, pp. 314-318.

Robertson G.R. (1959). The sampling variance of the genetic correlation coefficients, Biometrics ,no.15, pp. 494,

Dewey D.R. and K. Lu.(1959). A Correlation and Path-Coefficient Analysis of Components of Crested Wheatgrass Seed Production, Agronomy Journal, vol.51,no.9,pp.515-518.

Falconer, D.S. and Mackey T.F.C. 1996. Introduction to Quantitative Genetics. $4^{\text {th }}$ ed. Longman, Essex, England. p. 464

Mokhtassi B.A., Akbari G.A., Mirhadi M.J., Soufizadeh S. (2006). Path analysis of the relationships between seed yield and some morphological and phenological traits in safflower (Carthamustinctorius L.), Euphytica, no.148,pp, 261-268.

Gashaw, Z., Gebreselassie, W. and Hailemichael, G., 2020. Correlation and Path Coefficient Analysis in Yield and Yield-Related Components of Black Cumin (Nigella Sativa L.) Accessions, at Jimma, Southwest Ethiopia. International Journal of Agronomy

Bardideh, K., Kahrizi, D. And Ghobadi, M.E., 2013. Character association and path analysis of black cumin 
(Nigella sativa L.) Genotypes under different irrigation regimes. Notulae Scientia Biologicae, 5(1), pp.104108.

Tewodros L., Firew M. and Kebebew A.(2018). Correlation and Path Analysis for Yield and Yield component in Black Cumin (Nigella Sativa L.),International Journal of Current Research and Academic Review, vol.6,no.11,pp.56-63.

Miheretu F. (2018). Agronomic Performance, Genotype X Environment Interaction, and Stability of Black Cumin Genotypes Grown in Bale, Southeastern Ethiopia Advances in Crop Science and Technology, vol.6, no.3. doi: 10.4172/2329-8863.1000358.

Verma. Preeti, Solanki R.K., Dashora Abhay ,Kakani R.K. (2019). Genetic Variability and Correlation Analysis in Nigella (Nigella sativum L.) Assessed in South Eastern Rajasthan, India International Journal of Current Microbiology and Applied Sciences,vol. 2319-7706, no. 8, p 03.

Bardideh K., Kahrizi D., Ghobadi M.E. (2014).Character association and path analysis of black cumin (Nigella sativa L.) genotype under different irrigation regimes, Notulae ScientiaBiologicae, vol.5,no.1,pp.104-108. 